\title{
Comparison of radiofrequency and cryoablation procedures for mitral valve surgery patients with atrial fibrillation
}

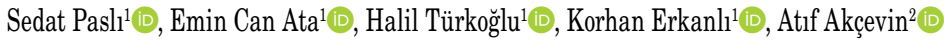 \\ 'Department of Cardiovascular Surgery, Medipol Mega University Hospital, Istanbul, Turkey \\ ${ }^{2}$ Department of Cardiovascular Surgery, Koç University Hospital, Istanbul, Turkey
}

Received: December 11, 2018 Accepted: January 18, 2019 Published online: April 24, 2019

\begin{abstract}
ABSTR ACT
Objectives: This study aims to compare the success of two different energy sources, radiofrequency versus cryoablation, in patients with atrial fibrillation.

Patients and methods: Between August 2012 and August 2017, a total of 55 patients (27 males, 28 females; mean age $51.6 \pm 11.2$ years; range, 44 to 71 years) with atrial fibrillation who underwent isolated left atrial ablation during mitral valve surgery in our clinic were included. Radiofrequency was applied to 41 patients and cryoablation to 14 patients. In both procedure, ablation was performed to isolate all pulmonary veins. Radiofrequency ablation utilized a RF current that was applied in a point-by-point mode, heating the tissue and leading to cellular necrosis. Cryogenic ablation induced necrosis by pumping refrigerant (nitrous oxide) through a balloon in a single-step mode, thereby freezing the tissue. The success of both techniques was evaluated through control echocardiography and electrocardiography.

Results: There was no statistically significant difference in the success rates of both techniques in terms of returning to the sinus rhythm. Two patients in the radiofrequency ablation group developed third-degree atrioventricular block with the need of permanent pacemaker implantation. In contrast no patient in the cryoablation group developed the same block. In patients who underwent radiofrequency ablation, the need for inotropic support in the postoperative period was higher with prolonged length of stay in the intensive care unit.

Conclusion: Our study results show that the success rate of both techniques is similar in patients with atrial fibrillation undergoing mitral valve surgery.
\end{abstract}

Keywords: Atrial fibrillation, cryoablation, radiofrequency ablation.

Atrial fibrillation (AF) is the most common chronic arrhythmia in clinical practice. Its incidence increases with age. Increased life expectancy in recent years has led to a rise in the incidence of AF. In earlier studies, the incidence was found to be $0.4 \%$ in the population and $4 \%$ in the age group above 65 years. ${ }^{[1,2]}$

The incidence of AF ranges between 30 and 90\% in patients with mitral valve disease. ${ }^{[3,4]}$ The risk of stroke in patients with AF is almost five to seven-times higher. ${ }^{[4]}$ This rate increases up to $17 \%$ annually in cases with mitral valve diseases. Atrial fibrillation is also responsible for $15 \%$ of all strokes. ${ }^{[5]}$

Mitral valve diseases have been implicated as one of the main causes of AF due to the high incidence of $\mathrm{AF}$ in these patients. However, the rate of return to sinus rhythm was found to be $23 \%$, if no additional treatment is given in addition to the surgical treatment. Some authors have shown that treatment of valvular disease alone remains insufficient. ${ }^{[6]}$ On the other hand, the rate of return to the sinus rhythm has been reported as 68 to $70 \%$ with ablation therapy in mitral valve disease. Based on these results, the treatment of AF has been also improved.$^{[6]}$

In the present study, we aimed to evaluate early results and possible complications of cryoablation and radiofrequency ablation in patients with $\mathrm{AF}$ undergoing mitral valve surgery.

Corresponding author: Emin Can Ata, MD. Medipol Mega Üniversite Hastanesi Kalp ve Damar Cerrahisi Bölümü, 34214 Bağcllar, İstanbul, Turkey. Tel: +90 212 - 4607777 e-mail: dr.enata@yahoo.com

\section{Citation:}

Paslı S, Ata EC, Türkoğlu H, Erkanlı K, Akçevin A. Comparison of radiofrequency and cryoablation procedures for mitral valve surgery patients with atrial fibrillation. Cardiovasc Surg Int 2019;6(1):7-11. 


\section{PATIENTS AND METHODS}

This retrospective study included a total of 55 patients ( 27 males, 28 females; mean age $51.6 \pm 11.2$ years; range, 44 to 71 years) with $\mathrm{AF}$ who underwent isolated left atrial ablation during mitral valve surgery at Medipol University Hospital, Department of Cardiovascular Surgery in our clinic between August 2012 and August 2017. Medical data of the patients were retrieved from the hospital records. Those with AF who underwent open heart surgery due to other indications were excluded. A written informed consent was obtained from each patient. The study protocol was approved by the Ethics Committee of Medipol University. The study was conducted in accordance with the principles of the Declaration of Helsinki.

Radiofrequency ablation was performed in 41 of 55 patients and cryoablation was performed in 11 patients. All patients had permanent AF for more than three months. All patients were using beta-blocker, calcium channel blocker, and digitalis for heart rate control in addition to vitamin $\mathrm{K}$ antagonist for preoperative persistent $\mathrm{AF}$.

Echocardiography (ECHO) and electrocardiography (ECG) measurements were recorded before and immediately after the operation and on the day of discharge and at one month postoperatively. All patients underwent isolated left atrial ablation with a radiofrequency catheter or cryoablation catheter. The left atrial appendix ostium was treated with box lesions which were created in such a way that the right and left pulmonary vein pair was separated and the boxes applied to the orifice of the pulmonary veins were combined with lesions to form a line lesion. The right line lesion was created to the P2-P3 leaflet of the mitral valve. The ablation period was approximately five to seven minutes with both methods. Ablation was performed in all patients prior to other surgical procedures. Left atrial appendage was closed in all patients. Epicardial temporary pacing was placed into the right ventricle and right atrium in all patients. Both ablation procedures were performed in the same region.

After the removal of the cross-clamp, all patients were treated with amiodarone $900 \mathrm{mg} / \mathrm{d}$ ay. Amiodarone $200 \mathrm{mg}$ tablets t.i.d. once daily for the maintenance therapy were continued for seven days, and then b.i.d once daily for one week, and one tablet for two weeks. Additionally, metoprolol was started at a dose of 25 to $100 \mathrm{mg}$ in all patients.

\section{Statistical analysis}

Statistical analysis was performed with PASW version 17.0 program (SPSS Inc., Chicago, IL, USA). The normal distribution of the variables was examined by histogram graphs and the KolmogorovSmirnov test. Mean, standard deviation, median and

\begin{tabular}{|c|c|c|c|}
\hline \multicolumn{4}{|c|}{$\begin{array}{c}\text { Table } 1 \\
\text { Baseline demographic and clinical characteristics of patients }\end{array}$} \\
\hline Parameters & $\mathrm{n}$ & $\%$ & Mean \pm SD \\
\hline Age (year) & & & $51.6 \pm 11.2$ \\
\hline $\begin{array}{l}\text { Gender } \\
\quad \text { Female } \\
\text { Male }\end{array}$ & $\begin{array}{l}28 \\
27\end{array}$ & $\begin{array}{l}50.9 \\
49.1\end{array}$ & \\
\hline Smoking & 10 & 18.2 & \\
\hline Alcohol & 6 & 10.9 & \\
\hline Height $(\mathrm{cm})$ & & & $164.0 \pm 8.9$ \\
\hline Weight $(\mathrm{kg})$ & & & $78.8 \pm 15.6$ \\
\hline Body mass index $\left(\mathrm{kg} / \mathrm{m}^{2}\right)$ & & & $29.0 \pm 6.9$ \\
\hline Preoperative heart rate (beat/min) & & & $84.1 \pm 14.2$ \\
\hline $\begin{array}{l}\text { Left atrium diameter } \\
\text { Radiofrequency patients }(\mathrm{cm}) \\
\text { Cryoablation patients }(\mathrm{cm})\end{array}$ & & & $\begin{array}{l}5.2 \pm 1.9 \\
5.1 \pm 2.7\end{array}$ \\
\hline
\end{tabular}




\begin{tabular}{|c|c|c|c|c|c|}
\hline \multicolumn{6}{|c|}{$\begin{array}{rr}\text { Table } 2\end{array}$} \\
\hline & \multicolumn{2}{|c|}{ Radiofrequency } & \multicolumn{2}{|c|}{ Cryoablation } & \multirow{2}{*}{$\frac{\text { Chi-square }}{p}$} \\
\hline & $\mathrm{n}$ & $\%$ & $\mathrm{n}$ & $\%$ & \\
\hline Early postoperative & 27 & 65.9 & 12 & 85.7 & 0.158 \\
\hline At discharge & 31 & 77.5 & 9 & 81.8 & 0.757 \\
\hline After one month & 33 & 82.5 & 9 & 81.8 & 0.958 \\
\hline
\end{tabular}

\begin{tabular}{|c|c|c|c|c|c|}
\hline & \multicolumn{2}{|c|}{ Radiofrequency } & \multicolumn{2}{|c|}{ Cryoablation } & \multirow[b]{2}{*}{$p$} \\
\hline & $\mathrm{n}$ & $\%$ & $\mathrm{n}$ & $\%$ & \\
\hline Yes & 38 & 92.7 & 9 & 64.3 & \\
\hline No & 3 & 7.3 & 5 & 35.7 & \\
\hline Total & 41 & & 14 & & 0.009 \\
\hline
\end{tabular}

\begin{tabular}{|c|c|c|c|c|c|}
\hline \multicolumn{6}{|c|}{$\begin{array}{c}\text { Table } 4 \\
\text { Pacemaker requirement following radiofrequency ablation versus cryoablation }\end{array}$} \\
\hline & \multicolumn{2}{|c|}{ Radiofrequency } & \multicolumn{2}{|c|}{ Cryoablation } & \multirow{2}{*}{$\begin{array}{c}\text { Chi-square } \\
p\end{array}$} \\
\hline & $\mathrm{n}$ & $\%$ & $\mathrm{n}$ & $\%$ & \\
\hline Yes & 16 & 39 & 4 & 28.6 & \\
\hline No & 25 & 61 & 10 & 71.4 & \\
\hline Total & 41 & & 14 & & 0.483 \\
\hline
\end{tabular}

minimum-maximum values were used to present descriptive analyzes. Pearson chi-square and Fisher's exact tests were compared with $2 \times 2$ Tables. While normally distributed (parametric) variables were evaluated among the groups, Student t-test was used. Mann-Whitney $U$ test was used to evaluate nonparametric variables. P-values $<0.05$ were evaluated as statistically significant results.

\section{RESULTS}

Of all patients, radiofrequency was applied to 41 patients $(74.5 \%)$ and cryoablation to 11 patients
(25.5\%). Baseline demographic and clinical characteristics of the patients are shown in Table 1.

In the early postoperative period, 27 (65.9\%) of radiofrequency patients returned to sinus rhythm, whereas $12(85.7 \%)$ of cryoablation patients returned to sinus rhythm, indicating no statistically significant difference. On the day of discharge, 31 (77.5\%) of radiofrequency patients and nine (81.8\%) of cryoablation patients were in sinus rhythm, indicating no statistically significant difference. Thirty three $(82.5 \%)$ versus nine patients $(81.8 \%)$ were still in sinus rhythm at one month (Table 2).

\section{Table 5}

Length of intensive care unit and hospital stay following radiofrequency ablation versus cryoablation

\begin{tabular}{|c|c|c|c|c|c|c|}
\hline & \multicolumn{2}{|c|}{ Radiofrequency } & \multicolumn{2}{|c|}{ Cryoablation } & \multirow[b]{2}{*}{$Z^{*}$} & \multirow[b]{2}{*}{$p$} \\
\hline & Mean & Min-Max & Mean & Min-Max & & \\
\hline Length of ICU stay (day) & 2.0 & $1.0-24.0$ & 1.0 & $1.0-24.0$ & -2.159 & 0.031 \\
\hline Length of hospital stay (day) & 10.0 & $7.0-34.0$ & 7.0 & $2.0-25.0$ & -3.151 & 0.002 \\
\hline
\end{tabular}


A total of 38 patients (92.7\%) who underwent radiofrequency ablation needed inotropic support, while nine $(64.3 \%)$ of the patients who underwent cryoablation needed inotropic support. The need for inotropic support was higher in patients who underwent radiofrequency (Table 3).

Sixteen (39.0\%) of the patients who underwent radiofrequency ablation and four $(28.6 \%)$ of the patients who underwent cryoablation required postoperative permanent pacemaker implantation. There was no statistically significant difference in the need for permanent pacemaker between the two ablation techniques (Table 4).

In addition, the length of hospital and intensive care unit stay was higher in the patients who were treated with radiofrequency ablation compared to those treated with cryoablation (Table 5).

\section{DISCUSSION}

Ablation procedures are recommended in the guidelines for patients with AF undergoing open heart surgery. ${ }^{[7]}$ Electrophysiological studies performed during the operation show that the focus of AF is concentrated in the orifice of the left atrium appendix and the left pulmonary veins, and in some patients, the focus is in the right pulmonary vein orifice. ${ }^{[8-10]}$ Based on previous study findings, isolated left atrial appendix procedures have been increasingly used. ${ }^{[11,12]}$

In our study, no significant difference was found between the two techniques. In similar studies in the literature, the rate of establishing the sinus rhythm was about 63 to $92 \%$ with radiofrequency ablation and 59 to $82 \%$ with cryoablation, ${ }^{[6,13]}$ consistent with our study results. However, delayed return to sinus rhythm was observed in long-term follow-up patients who were ablated for AF. ${ }^{[14,15]}$

Although there are many studies using energy sources and procedures, no consensus has been established, yet. Previous studies using similar methods demonstrated similar rates of sinus node dysfunction, nodal rhythm, and complete atrioventricular block (AV) block rates in the early postoperative period. In our study, no atrial flutter was seen, compared to the other studies, which was found to be 4 to $6 \%$ of occurrence. ${ }^{[16-18]}$ Meta-analyses showed that the rate of permanent pacemaker requirement in patients undergoing radiofrequency ablation procedure ranged from 0 to $10 \%$ and the rate of patients who required permanent pacemakers in patients undergoing cryoablation procedure was 0 to $21 \% \cdot \cdot^{[7,13]}$ In our study, two patients who underwent radiofrequency ablation required permanent pacemaker implantation due to complete AV block; however, none of the cryoablation patients required permanent pacemaker.

In the literature, isolated left atrial ablation-related complications such as esophageal injury, trachea injury, circumflex artery injury, and pulmonary vein stenosis have been reported. ${ }^{[19-22]}$ It was also shown that patients undergoing maze procedure had longer hospitalizations, but there were no differences between the ablation methods. ${ }^{[23]}$ In our study, these complications were not encountered, although the need for inotropic support was found to be higher with longer intensive care unit and hospital stay in the patients who underwent radiofrequency ablation than cryoablation. In another study, the risk of thromboembolism was found to be higher in the radiofrequency ablation group than cryoablation, ${ }^{[24]}$ although thromboembolism complications were not seen in both methods in our study.

In conclusion, our study results suggest that radiofrequency ablation and cryoablation can be used in patients with atrial fibrillation scheduled for open heart surgery. The success rate of both techniques is also similar in our study. However, further, large-scale and long-term studies are needed to fully elucidate the effects of both energy sources.

\section{Declaration of conflicting interests}

The authors declared no conflicts of interest with respect to the authorship and/or publication of this article.

\section{Funding}

The authors received no financial support for the research and/or authorship of this article.

\section{REFERENCES}

1. Kannel WB, Abbott RD, Savage DD, McNamara PM. Epidemiologic features of chronic atrial fibrillation: the Framingham study. N Engl J Med 1982;306:1018-22.

2. Go AS, Hylek EM, Phillips KA, Chang Y, Henault LE, Selby JV, et al. Prevalence of diagnosed atrial fibrillation in adults: national implications for rhythm management and stroke prevention: the AnTicoagulation and Risk Factors in Atrial Fibrillation (ATRIA) Study. JAMA 2001;285:2370-5.

3. Feinberg WM, Blackshear JL, Laupacis A, Kronmal R, Hart RG. Prevalence, age distribution, and gender of patients 
with atrial fibrillation. Analysis and implications. Arch Intern Med 1995;155:469-73.

4. Wolf PA, Abbott RD, Kannel WB. Atrial fibrillation as an independent risk factor for stroke: the Framingham Study. Stroke 1991;22:983-8.

5. Ezekowitz MD, Netrebko PI. Anticoagulation in management of atrial fibrillation. Curr Opin Cardiol 2003;18:26-31.

6. Cheng DC, Ad N, Martin J, Berglin EE, Chang BC, Doukas $G$, et al. Surgical ablation for atrial fibrillation in cardiac surgery: a meta-analysis and systematic review. Innovations (Phila) 2010;5:84-96.

7. Dunning J, Nagendran M, Alfieri OR, Elia S, Kappetein AP, Lockowandt $\mathrm{U}$, et al. Guideline for the surgical treatment of atrial fibrillation. Eur J Cardiothorac Surg 2013;44:777-91.

8. Haissaguerre $M$, Fischer $B$, Labbé $T$, Lemétayer $P$, Montserrat $\mathrm{P}$, d'Ivernois $\mathrm{C}$, et al. Frequency of recurrent atrial fibrillation after catheter ablation of overt accessory pathways. Am J Cardiol 1992;69:493-7.

9. Sueda T, Imai K, Ishii O, Orihashi K, Watari M, Okada K. Efficacy of pulmonary vein isolation for the elimination of chronic atrial fibrillation in cardiac valvular surgery. Ann Thorac Surg 2001;71:1189-93.

10. Yamauchi S, Ogasawara H, Saji Y, Bessho R, Miyagi Y, Fujii M. Efficacy of intraoperative mapping to optimize the surgical ablation of atrial fibrillation in cardiac surgery. Ann Thorac Surg 2002;74:450-7.

11. Sueda T, Nagata H, Orihashi K, Morita S, Okada K, Sueshiro $\mathrm{M}$, et al. Efficacy of a simple left atrial procedure for chronic atrial fibrillation in mitral valve operations. Ann Thorac Surg 1997;63:1070-5.

12. Arcidi JM Jr, Doty DB, Millar RC. The Maze procedure: the LDS Hospital experience. Semin Thorac Cardiovasc Surg 2000;12:38-43.

13. Khargi K, Hutten BA, Lemke B, Deneke T. Surgical treatment of atrial fibrillation; a systematic review. Eur J Cardiothorac Surg 2005;27:258-65.

14. McCarthy PM, Gillinov AM, Castle L, Chung M, Cosgrove D. The Cox-Maze procedure: the Cleveland Clinic experience. Semin Thorac Cardiovasc Surg 2000;12:25-9.
15. Kress DC, Krum D, Chekanov V, Hare J, Michaud N, Akhtar M, et al. Validation of a left atrial lesion pattern for intraoperative ablation of atrial fibrillation. Ann Thorac Surg 2002;73:1160-8.

16. Hornero Sos F, Montero Argudo JA, Rodríguez Albarrán I, Bueno Codoñer M, Buendía Miñano J, Gil Albarova O, et al. Ablation of permanent atrial fibrillation in cardiac surgery. Short-term and mid-term results. Rev Esp Cardiol 2004;57:939-45.

17. Chen MC, Guo GB, Chang JP, Yeh KH, Fu M. Radiofrequency and cryoablation of atrial fibrillation in patients undergoing valvular operations. Ann Thorac Surg 1998;65:1666-72.

18. Mohr FW, Fabricius AM, Falk V, Autschbach R, Doll N, Von Oppell U, et al. Curative treatment of atrial fibrillation with intraoperative radiofrequency ablation: short-term and midterm results. J Thorac Cardiovasc Surg 2002;123:919-27.

19. Doll N, Borger MA, Fabricius A, Stephan S, Gummert J, Mohr FW, et al. Esophageal perforation during left atrial radiofrequency ablation: Is the risk too high? J Thorac Cardiovasc Surg 2003;125:836-42.

20. Gillinov AM, Pettersson G, Rice TW. Esophageal injury during radiofrequency ablation for atrial fibrillation. J Thorac Cardiovasc Surg 2001;122:1239-40.

21. Demaria RG, Pagé P, Leung TK, Dubuc M, Malo O, Carrier $\mathrm{M}$, et al. Surgical radiofrequency ablation induces coronary endothelial dysfunction in porcine coronary arteries. Eur J Cardiothorac Surg 2003;23:277-82.

22. Güden M, Akpinar B, Sanisoglu I, Sagbas E, Bayindir O. Intraoperative saline-irrigated radiofrequency modified Maze procedure for atrial fibrillation. Ann Thorac Surg 2002;74:1301-6.

23. Handa N, Schaff HV, Morris JJ, Anderson BJ, Kopecky SL, Enriquez-Sarano M. Outcome of valve repair and the Cox maze procedure for mitral regurgitation and associated atrial fibrillation. J Thorac Cardiovasc Surg 1999;118:628-35.

24. Khairy P, Chauvet P, Lehmann J, Lambert J, Macle L, Tanguay JF, et al. Lower incidence of thrombus formation with cryoenergy versus radiofrequency catheter ablation. Circulation 2003;107:2045-50. 